\title{
Peripheral Giant Cell Granuloma of Posterior Maxilla in a 9-Year Child
}

\author{
Hamza Hassan Mirza ${ }^{1}$, Abul Khair Zalan², Anser Maxood ${ }^{3}$ Anika Gul ${ }^{4}$, Zainab Memon² and Muhammad \\ Sulaiman $^{5}$ \\ ${ }^{1}$ Department of Oral and Maxillofacial Surgery, Pakistan Institute of Medical Sciences, Islamabad, Pakistan \\ ${ }^{2}$ Department of Paediatric Dentistry, Pakistan Institute of Medical Sciences, Islamabad, Pakistan \\ ${ }^{3}$ Department of Operative and Pediatric Dentistry, Pakistan Institute of Medical Sciences, Islamabad, Pakistan \\ ${ }^{4}$ Department of Pediatric Dentistry, Kohat Dental Institute, Kohat, Pakistan \\ ${ }^{5}$ Department of Oral and Maxillofacial Surgery, Khyber College of Dentistry, Peshawar, Pakistan
}

\begin{abstract}
Peripheral giant cell granuloma is a relatively uncommon benign reactive gingival lesion of the oral cavity. A 9-year boy presented with a painless, slow-growing, reddish-blue, soft tissue lesion on attached gingiva adjacent to maxillary right first and second premolars, which was interfering with eating. A periapical radiograph demonstrated focal alveolar bone loss and slight teeth displacement adjacent to the lesion. Diagnosis of peripheral giant cell granuloma was made through clinical and radiographic evaluation, by its typical presentation and correlation with histopathologic findings. Complete excision was carried out down to the underlying bone. A follow-up visit was scheduled after 7 days and deep scaling was performed. There was no recurrence three months post-excision. Timely detection and excision of this lesion is important to avoid future dentoalveolar problems.
\end{abstract}

Key Words: Giant cell granuloma, Benign, Peripheral, Child.

How to cite this article: Mirza HH, Zalan AK, Maxood A, Gul A, Memon Z, Sulaiman M. Peripheral Giant Cell Granuloma of Posterior Maxilla in a 9-Year Child. J Coll Physicians Surg Pak 2021; 31(04):475-477.

\section{INTRODUCTION}

The peripheral giant cell granuloma has been described in the literature for many years under a variety of names, with the most common being "peripheral giant cell reparative granuloma." ${ }^{1}$ It arises principally from the periodontal membrane, gingival connective tissue, or periosteum of alveolus. ${ }^{2}$ The initial stimulus can be local irritation or trauma but the exact cause of the lesion is not clearly understood. It can occur in any site on the gingival mucosa but mostly develops in anterior to molars. The age of onset is first to sixth decades of life with an almost 2:1 female predilection and occurs more commonly in the mandible than the maxilla. ${ }^{3}$ Clinically, it appears as a red or red-blue lobular mass that is sessile or pedunculated. Most lesions are smaller than $2 \mathrm{~cm}$ in diameter. ${ }^{4}$ Surface ulceration, bleeding and displacement ofteeth are commonfindings. Radiographs often reveal superficial resorption or cupping of alveolar bone. $^{5}$

Correspondence to: Dr. Hamza Hassan Mirza, Department of Oral and Maxillofacial Surgery, Pakistan Institute of Medical Sciences, Islamabad, Pakistan

E-mail: hamzahassan 91@live.com

Received: August 29, 2019; Revised: November 28, 2019; Accepted: December 12, 2019

DOI: https://doi.org/10.29271/jcpsp.2021.04.475

\section{CASE REPORT}

A nine-year child presented to the outpatient department of pediatric dentistrywith the complaint of swelling in right upper jaw since five months that was slowly enlarging and interfering with eating (Figure 1). There was no history of trauma. Family and medical history were not significant. Oral hygiene of the patient was not satisfactory. There was no complaint of pain or spontaneous bleeding. However, the lesion occasionally bled slightly on manipulation.

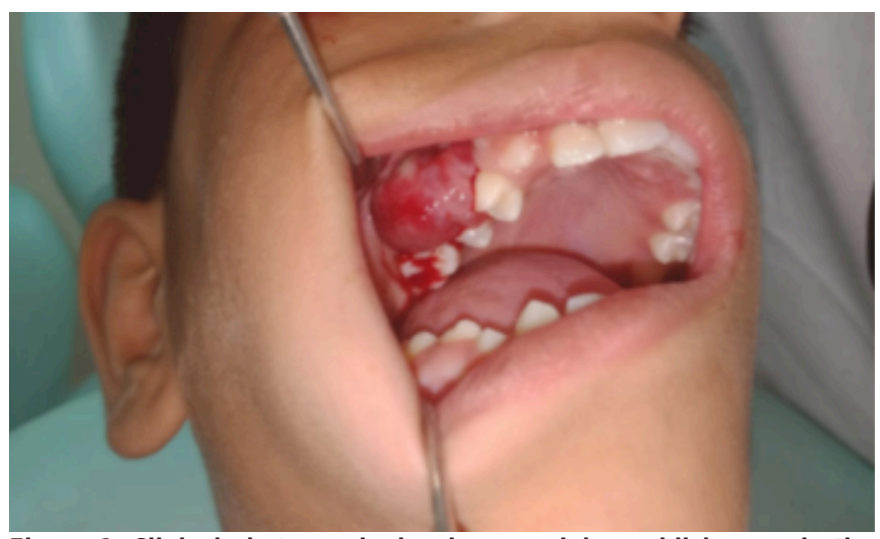

Figure 1: Clinical photograph showing a nodular reddish mass in the gingiva of upper posteriormaxilla.

On examination, the patient had a facial swelling of his right posterior maxilla extraorally. There was no associated lympha- 
denopathy. Intraorally, there was a $22 \times 16 \times 11 \mathrm{~mm}$ pedunculated, nodular reddish mass on gingiva adjacent to maxillary right first and second premolar, extending to the inter-dental area (Figure 2). The adjacent teeth were non-mobile, but were slightly displaced palatally. The mass was firm in consistency on palpation. The outer covering of the mass was reddish with central ulceration. Intraoral periapical radiograph was taken, which revealed resorption of alveolar bone (Figure 3).

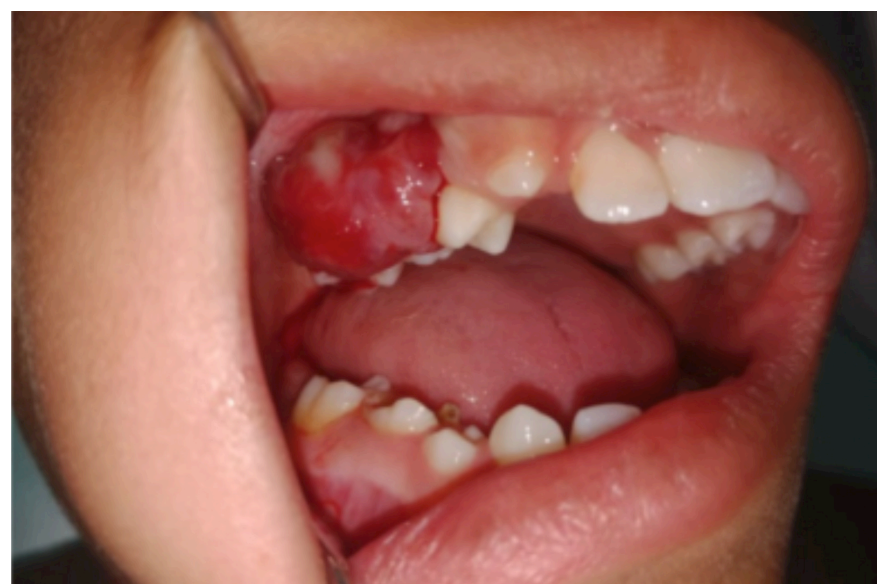

Figure 2: Close-up view showing the mass and palatally displaced upper maxillary teeth.

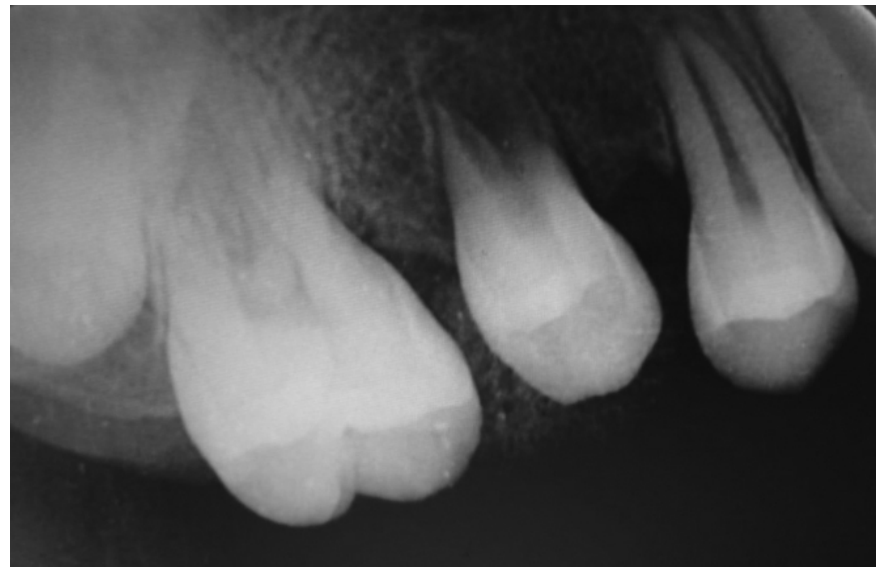

Figure 3: Intraoral periapical radiograph showing resorption of alveolar bone caused by the mass.

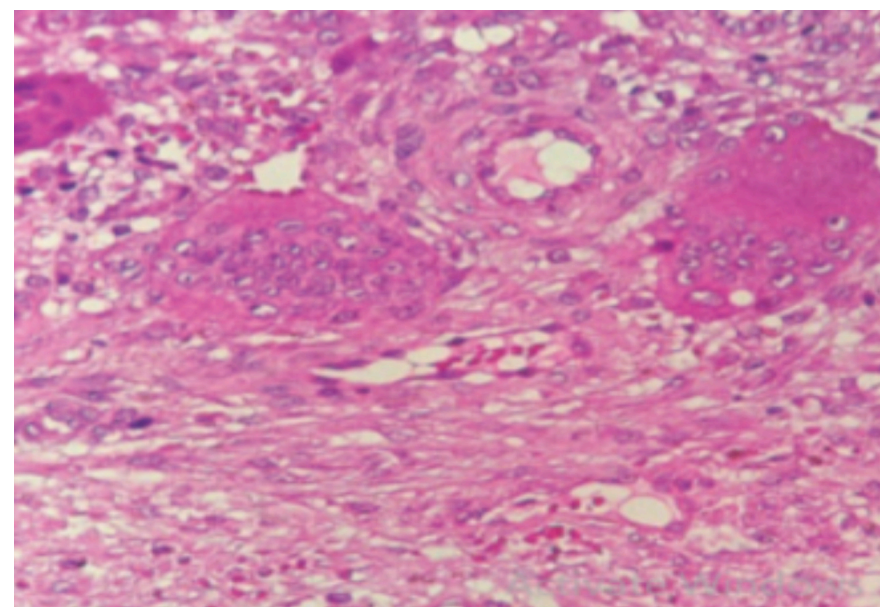

Figure 4: Histopathology of the mass lesion benign giant cell lesion consistent with giant cell reparative granuloma.
The lesion was planned for complete surgical removal under local anesthesia. Excision was carried out down to the underlying bone including the interdental area, along with curettage, to lessen the chances of recurrence. Bleeding was controlled with cauterisation and a periodontal dressing applied to cover the surgical site. The entire specimen was submitted for histopathologic examination. On a recall visit of one week, deep scaling was done to remove the irritating factors, which were possible cause of the lesion.

Specimen revealed tissue lined by stratified squamous epithelium. Sub-epithelial tissue showed evenly distributed numerous giant cells, granulation tissue, and blood vessels with areas of hemorrhage within stroma consisting of spindle-shaped and ovoid mesenchymal cells (Figure 4).

The patient was recalled after every month. No recurrence has been reported three months post-excision (Figure 5).

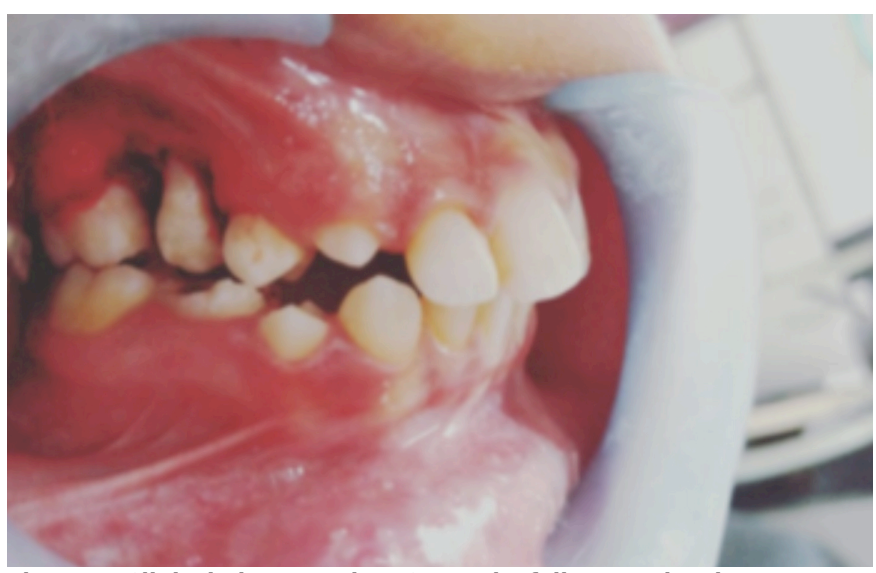

Figure 5: Clinical photograph at 3 months follow-up showing no recurrence of the lesion.

\section{DISCUSSION}

While peripheral giant cell granuloma mostly occurs in adults, there are reports of cases in children where lesions have shown more aggressive clinical behaviour. It can cause superficial bone loss, hinder tooth eruption and can displace erupted teeth adjoining the lesion. ${ }^{6}$

Clinically, it has been found that the incidence rate of peripheral giant cell granuloma among all oral soft tissue lesions varies from $5.1 \%$ to $43.6 \%$. The age incidence is mostly in the fourth to sixth decade of life with a slight female predilection, occurring more commonly in the mandible. ${ }^{7}$

The typical clinical presentation is a swelling of up to $2 \mathrm{~cm}$ in diameter with a firm or soft consistency. They may have a sessile or pedunculated base involving alveolar or gingival mucosa. The color ranges from red to dark-red to bluish with or withoutulceration. Pain is not a routine finding. ${ }^{8}$

Radiographic features are generally non-specific. There may be no significant radiologic changes in some lesions. However, superficial destruction of alveolar bone with the displacement of adjacent teeth has been seen, as in our case. Periodontal ligament widening has also been noted in some cases. 
Other lesions showing similar features include pyogenic granuloma, peripheral ossifying fibroma, peripheral odontogenic fibroma and hemangioma. Pyogenic granuloma appears as a soft, lobular mass that bleeds easily. However, displacement of teeth and loss of alveolar bone do not occur. Peripheral ossifying fibroma shows similar clinical features as well, but lacks the bluish-purple discoloration and can contain flecks of calcification which help to differentiate it from peripheral giant cell granuloma. Hemangiomas show similarities as well, but brisk haemorrhage, increased tissue temperature, and blanching upon palpation are characteristics of this lesion. ${ }^{9}$

Surgical excision down to the bone is the mainstay of treatment, to remove any source of irritation. If the lesion is not excised completely, recurrence will inevitably occur in most of the cases. The average rate of recurrence has been shown to be about $9.9 \%$ taken from numerousstudies. ${ }^{10}$

Timely diagnosis of peripheral giant cell granuloma aided by clinical, radiological, and histopathologic evaluation is important to allow for conservative surgical approach to avoid potential hazards to adjacent hard tissues.

\section{PATIENT'S CONSENT:}

Informed consent was obtained from the patient.

\section{CONFLICT OF INTEREST:}

The authors declared no conflict of interest.

\section{AUTHORS' CONTRIBUTION:}

HHM: Drafted the case report from the collected data.

AKZ: Collected the data for the manuscript.

AM: Edited the manuscript for the final version before submission.

$A G$ : Revised the references and interpreted the data.

ZM: Conception of study and procedure.

MS: Designed the format of manuscript and integration of images.

\section{REFERENCES}

1. Ertugrul AS, Genc S. Peripheral giant cell granuloma treatment with guided tissue regeneration: Case report. J Dent and Oral Care 2016; 2(2):88-90. DOI: 10.15436/ 2379-1705.16.1176

2. Adlakha V, Chandna P, Rehani U, Rana V, Malik P. Peripheral giant cell granuloma. Journal of Indian Society of Pedodontics and Preventive. Dent 2010; 28(4):293-6.

3. Nekouei A, Eshghi A, Jafarnejadi P, Enshaei Z. A review and report of peripheral giant cell granuloma in a 4-year-old child. Case reports in dent 2016; 2016: Article ID 7536304. DOI: 10.1155/2016/7536304

4. Jindal DG, Kushwaha SS, Joshi S, Sepolia N, Jindal V, Jain K. Peripheral giant cell granuloma: A Case report with review on its histogenesis and recurrence. Dent J Adv Studies 2019; 7(2): DOI: 10.1055/s-0039-1688548

5. Flaitz CM. Peripheral giant cell granuloma: A potentially aggressive lesion in children. Pedia Dent 2000; 22(3): 232-3.

6. Mukherjee CG, Mukherjee U, Bansal A, Mukhopadhyay M. Giant cell granuloma: Two expressions in pediatric population. Intern J Clin Pediatr Dent 2018; 11(1):46-9. doi: 10.5005/jp-journals-10005-1482.

7. Khandelwal D, Khatri A, Kalra N, Tyagi R, Banga A, Panwar G. Peripheral giant cell granuloma: An unusual presentation in pediatric patient: A report of two cases. SRM J Res Dental Sci 2016; 7(4):259.

8. Han J, Park MK, Lee J, Choi BJ, Kim SO. Peripheral giant cell granuloma associated with the eruption of a maxillary central incisor. J Korean Acad Ped Dent 2017; 44(4): 469-73.

9. Nagaraj T, Balraj L, Sinha P, Narayanan S. Peripheral giant cell granuloma: A case report and review. Intern Jour of Medi and Dent Case Rep 2017; 4(1):1-3.

10. Maheshwari S, Bhutada G, Baisane V, Palve D. Peripheral giant cell granuloma: A review and case report. Intern J Healthcare and Biomed Res 2017; 5(02):53-8... 